\title{
Macrominerais para bovinos de corte nas pastagens nativas dos Campos de Cima da Serra - RS
}

\author{
Macro minerals to beef cattle in the native pastures of Campos de Cima da Serra-RS, Brazil
}

\section{Carolina Wunsch $^{1}$ Júlio Otávio Jardim Barcellos ${ }^{2}$ Ênio Rosa Prates ${ }^{3}$ Eduardo Castro da Costa ${ }^{4}$ Yuri Regis Montanholi ${ }^{5}$ Fernanda Brandão ${ }^{6}$}

\section{RESUMO}

Em face das poucas informações disponíveis sobre a composição mineral das pastagens nativas da região dos Campos de Cima da Serra (RS), o presente trabalho de pesquisa objetivou avaliar os teores dos principais macrominerais, em diferentes épocas do ano, e relacionar o perfil mineral destas pastagens com as necessidades nutricionais recomendadas pelo NRC (1996) para bovinos de corte. O projeto foi conduzido em vinte propriedades particulares, em Cambará do Sul, utilizando áreas de campo nativo que estavam sendo normalmente utilizadas em pastoreio por bovinos de corte elou ovinos e que não tinham sofrido nenhum tipo de melhoria, reforma ou recuperação (exceto queimada), no mínimo nos últimos 20 anos. Colheram-se, durante oito meses, e dentro de uma mesma área predeterminada em cada propriedade, amostras para determinar as concentrações de $\mathrm{Ca}, \mathrm{P}, \mathrm{Mg}$, Na e S. Verificou-se efeito do mês de coleta sobre todos os minerais analisados. Foram constatados teores suficientes de Ca e Mg para as categorias de bovinos de corte menos exigentes. Os teores de $\mathrm{Mg}$ são deficientes para vacas em gestação e lactação e os teores de Ca são deficientes para terneiros. Por outro lado, os teores de P, Na e S apresentaramse abaixo das exigências mínimas para as categorias de bovinos de corte avaliadas.

Palavras-chave: bovinos de corte, minerais, pastagem nativa, exigências nutricionais, nutrição mineral.

\section{ABSTRACT}

The present study was conducted to determine the mineral status of natural range pastures of Campos de Cima da Serra region, State of Rio Grande do Sul, Brazil, in different months of the year, to compare them to beef cattle requirements (NRC, 1996). The project was led in twenty private farms, in Cambará do Sul county, on grazing areas without improvements (except burning) at the last twenty years. Pasture samples were collected at January, February, March April, May, July, September and December to determine its calcium, phosphorus, magnesium, sodium and sulphur levels. Effect of the season was verified on all analyzed minerals. The Ca and Mg contents on grass samples were higher than the less demanding beef cattle categories requirements. Mg levels were deficient for more demanding animal categories, like gestating and lactating cows. Ca levels were deficient for calves. However, $\mathrm{P}, \mathrm{Na}$ and $\mathrm{S}$ contents were lower than required for beef cattle categories.

Key words: beef cattle, minerals, native pasture, animal requirements, mineral nutrition.

\section{INTRODUÇÃO}

A produção de carne bovina no Rio Grande do Sul é sustentada basicamente por sistemas a pasto, especialmente por pastagens naturais. Além disso, pela expansão dos cultivos agrícolas, serão destinados à bovinocultura de corte solos de menor fertilidade e, como resultado, pastagens de pior qualidade.

Assim, os bovinos criados a pasto estarão susceptíveis às deficiências minerais, as quais constituem uma grave limitação à produção. Tanto a

\footnotetext{
${ }^{1}$ Universidade Estadual do Rio Grande do Sul (UERGS), Porto Alegre, RS, Brasil.

${ }^{2}$ Departamento de Zootecnia, Faculdade de Agronomia, Universidade Federal do Rio Grande do Sul (UFRGS), CP 776, 91540-000,

Porto Alegre, RS, Brasil. E-mail: julio.barcellos@ufrgs.br. Autor para correspondência.

${ }^{3}$ Departamento de Zootecnia, Faculdade de Agronomia, UFRGS, Porto Alegre, RS, Brasil.

${ }^{4}$ Curso de Pós-graduação em Zootecnia, UFRGS, Porto Alegre, RS, Brasil.

${ }^{5}$ Curso de Pós-graduação em Ciência Animal, Universidade de Guelph, Guelph, Canadá.

${ }^{6}$ Curso de Medicina Veterinária, UFRGS, Porto Alegre, RS, Brasil.
} 
deficiência severa de minerais, muitas vezes acompanhada por elevadas taxas de mortalidade, bem como as deficiências subclínicas ou marginais, podem levar a perdas consideráveis na produtividade.

Para animais em pastejo, que têm sua fonte de alimentação na pastagem nativa, os desbalanços minerais que eventualmente podem aparecer têm um dos meios de sua verificação na análise da pastagem (BARCELLOS et al., 2003). Ainda, existe uma nítida influência do clima na composição mineral e nutricional das plantas, indicando a necessidade de avaliar os seus teores de minerais em diferentes estações do ano para ter de forma mais clara uma estimativa da sua composição (UNDERWOOD \& SUTTLE, 1999).

No Brasil, resultados de análises de solos, de plantas forrageiras e de tecidos animais têm revelado ampla variedade de carências e algumas toxicidades de minerais (TOKARNIA et al., 2000).

Em face das poucas informações disponíveis sobre a composição mineral das forrageiras na região dos Campos de Cima da Serra, no Rio Grande do Sul, o presente trabalho objetivou avaliar os teores dos macrominerais cálcio, fósforo, magnésio, sódio e enxofre nas pastagens características dessa região, em diferentes épocas do ano, e relacionar o perfil mineral dessas pastagens com as necessidades nutricionais recomendadas pelo NRC (1996) para as diferentes categorias de bovinos de corte, a fim de estabelecer a necessidade ou não de suplementação dos minerais analisados.

\section{MATERIAL E MÉTODOS}

O experimento foi realizado no Município de Cambará do Sul, na região norte do Estado do Rio Grande do Sul. Foi avaliada, durante o ano de 2003, a composição dos principais minerais da pastagem natural característica da região dos Campos de Cima da Serra. As características de clima, solo e vegetação dessa região foram descritas por WUNSCH et al. (2005).

Foram selecionados vinte locais de coleta, representados por propriedades rurais da região, para a obtenção das amostras de pastagem natural. Com a finalidade de observar possíveis variações nas concentrações de cálcio $(\mathrm{Ca})$, fósforo $(\mathrm{P})$, sódio $(\mathrm{Na})$, enxofre $(\mathrm{S})$ e magnésio $(\mathrm{Mg})$, foram efetuadas oito coletas durante o ano de realização do trabalho (2003), sendo duas coletas no verão, três no outono, duas no inverno e uma coleta na primavera.

O material foi cortado manualmente com tesoura inoxidável em um quadrado de $0,25 \mathrm{~m}^{2}$, rente ao solo, e acondicionado em sacos de polietileno. Posteriormente, o material foi pesado para determinação da disponibilidade de matéria seca (MS), secado em estufa de circulação forçada de ar, a $65^{\circ} \mathrm{C}$, por 72 horas, pesado novamente e moído em moinho tipo Willey com peneira de $1 \mathrm{~mm}$.

As amostras foram analisadas no laboratório da empresa Rodes Química, em Cajati, SP, para determinação dos teores minerais ( $\mathrm{Ca}, \mathrm{P}$ e $\mathrm{Mg}$ ) e proteína (PB) e no Laboratório de Análises de Solos da Universidade Federal do Rio Grande do Sul para análises de $\mathrm{Na}$ e S. Os teores de PB, P, Ca e Mg foram obtidos segundo AOAC (1984) e os teores de Na e S foram determinados conforme TEDESCO et al. (1995).

O delineamento experimental utilizado foi o completamente casualizado. Para a interpretação estatística dos resultados, utilizou-se o modelo GLM (General Linear Model) do programa estatístico SPSS 11.5 (2002), segundo o modelo: $\mathrm{Yij}=\mathrm{M}+\mathrm{Pi}+\mathrm{Ci}+\mathrm{Eij}$, onde: Yij = Valor observado; $\mathrm{M}=$ Efeito médio; $\mathrm{Pi}=$ Efeito da propriedade; $\mathrm{Ci}$ = Efeito do mês de coleta; Eij = Erro. A comparação entre médias foi efetuada pelo teste de Tukey, assumindo-se 5\% de probabilidade de erro.

\section{RESULTADOS E DISCUSSÃO}

As pastagens nativas da região apresentavam uma boa disponibilidade de matéria seca $\left(2.035 \mathrm{~kg}^{-1}\right)$, mas de baixa qualidade (5,60\% de PB). Ao longo do ano, verificou-se efeito $(\mathrm{P}<0,01)$ dos meses de coleta sobre os teores médios de cálcio, fósforo, enxofre, sódio e magnésio nas pastagens.

Os teores de cálcio nas pastagens estudadas variaram de 0,17 a 1,73\%, e os níveis médios de cálcio, além de outros macronutrientes, são apresentados na tabela 1 . O valor mais alto de cálcio, observado no mês de setembro, coincide com o final do inverno, quando as pastagens apresentam-se em elevado estágio de maturidade. No restante do período de observação, os teores de cálcio permaneceram semelhantes, apenas com uma tendência a valores mais baixos em fevereiro. Além disso, no mês de fevereiro, ocorreu o maior volume de precipitação pluviométrica, o que pode explicar essa variação (GEORGIEVSKII et al., 1982).

Neste trabalho, foram encontrados teores de cálcio um pouco superiores aos observados por GAVILLON \& QUADROS (1970), que obtiveram, em pastagens nativas do RS, teores médios de 0,29\% na primavera e de 0,27\% no verão. Já AGOSTINI (1976), em dez unidades de mapeamento de solos no RS, encontrou teores médios de $0,43 \%$ de cálcio na primavera e de $0,34 \%$ no verão. CAVALHEIRO \& TRINDADE (1992), nas regiões da Campanha e da 
Tabela 1 - Teores médios de cálcio (Ca), fósforo $(\mathrm{P})$, enxofre (S), sódio (Na) e magnésio (Mg) e relação Ca:P na MS em pastagens nativas dos Campos de Cima da Serra avaliadas em diferentes meses do ano.

\begin{tabular}{|c|c|c|c|c|c|c|}
\hline Mês de coleta & Ca (\%) & P (\%) & S (\%) & $\mathrm{Na}(\mathrm{ppm})$ & Mg (ppm) & $\mathrm{Ca}: \mathrm{P}$ \\
\hline jan & $0,42^{\mathrm{ab}}$ & $0,08^{\mathrm{ab}}$ & $0,09^{\mathrm{a}}$ & $178,0^{\mathrm{bc}}$ & $1062,4^{\mathrm{ab}}$ & $4,8: 1$ \\
\hline fev & $0,29^{b}$ & $0,08^{\mathrm{abc}}$ & $0,08^{\text {cd }}$ & $159,8^{\mathrm{bc}}$ & $1054,1^{\mathrm{ab}}$ & $3,6: 1$ \\
\hline mar & $0,39^{\mathrm{b}}$ & $0,08^{\mathrm{abc}}$ & $0,08^{\text {bcd }}$ & $211,7^{\mathrm{ab}}$ & $1061,9^{\mathrm{ab}}$ & $4,8: 1$ \\
\hline $\mathrm{abr}$ & $0,40^{\mathrm{b}}$ & $0,07^{\mathrm{bc}}$ & $0,07^{d}$ & $144,8^{\mathrm{bc}}$ & $893,6^{b}$ & $5,7: 1$ \\
\hline mai & $0,42^{\mathrm{ab}}$ & $0,07^{\mathrm{bc}}$ & $0,08^{\text {cd }}$ & $170,7^{\mathrm{bc}}$ & $1027,0^{\mathrm{ab}}$ & $5,9: 1$ \\
\hline jul & $0,41^{\mathrm{ab}}$ & $0,06^{\mathrm{c}}$ & $0,09^{\mathrm{abc}}$ & $174,5^{\mathrm{bc}}$ & $995,1^{\mathrm{ab}}$ & $6,5: 1$ \\
\hline set & $0,57^{\mathrm{a}}$ & $0,07^{\mathrm{abc}}$ & $0,07^{\mathrm{d}}$ & $104,7^{\mathrm{c}}$ & $870,7^{\mathrm{b}}$ & $7,3: 1$ \\
\hline dez & $0,42^{\mathrm{ab}}$ & $0,09^{\mathrm{a}}$ & $0,09^{\mathrm{ab}}$ & $254,7^{\mathrm{a}}$ & $1141,5^{\mathrm{ab}}$ & $4,5: 1$ \\
\hline Média & 0,41 & 0,07 & 0,08 & 174,8 & 1015,2 & $5,3: 1$ \\
\hline Desvio padrão & 0,17 & 0,02 & 0,01 & 135,4 & 248,9 & - \\
\hline
\end{tabular}

a,b,c Letras diferentes na coluna diferem significativamente $(\mathrm{P}<0,05)$.

Depressão Central do RS, constataram teores médios de cálcio nas pastagens nativas de $0,24 \%$ no verão e de $0,32 \%$ nas outras estações do ano.

É possível que estas variações observadas nos níveis de cálcio em relação a outras pesquisas sejam devidas a diferenças de solos e da composição botânica de cada região. As influências desses fatores foram observadas por WUNSCH et al. (2005), quantificando os teores de microminerais para bovinos de corte no Rio Grande do Sul.

Por outro lado, na região do presente trabalho, HERINGER \& JACQUES (2002) encontraram teores de cálcio bem mais baixos, de 0,15 e 0,16\%, em pastagens sem queima e sem roçada e em pastagens com queima anual, respectivamente. É possível que essas diferenças sejam devidas ao tipo de solo em que foi conduzido o levantamento.
A relação Ca:P observada sempre foi alta, variando de 3,6:1 em fevereiro até 7,3:1 em setembro (Tabela 1). Apesar de não ser possível estabelecer com certeza a ótima relação $\mathrm{Ca} P \mathrm{P}$, existem algumas evidências de que uma alta relação $\mathrm{Ca}: \mathrm{P}$ possa reduzir o ganho de peso, devido a uma redução da digestibilidade da dieta (McDOWELL, 1992), principalmente quando os teores de fósforo não são supridos adequadamente.

A comparação dos níveis de cálcio encontrados nas pastagens com as exigências de bovinos de corte em crescimento e terminação estimadas pelo NRC (1996) demonstra que a pastagem da região do experimento é capaz de suprir adequadamente estas categorias animais, exceto os terneiros desmamados precocemente (Tabela 2).

Tabela 2 - Balanço mineral do cálcio e fósforo nas pastagens nativas dos Campos de Cima da Serra para bovinos de corte em crescimento e terminação.

\begin{tabular}{|c|c|c|c|c|c|c|}
\hline \multirow[t]{2}{*}{ Categoria } & \multirow{2}{*}{$\begin{array}{l}\text { Peso vivo } \\
\text { (kg) }\end{array}$} & \multirow{2}{*}{$\begin{array}{l}\text { Taxa de ganho } \\
\text { (kg/dia) }\end{array}$} & \multicolumn{2}{|c|}{ Exigência* (\% MS) } & \multicolumn{2}{|c|}{ Balanço mineral para todo o ano } \\
\hline & & & $\mathrm{Ca}$ & $\mathrm{P}$ & $\mathrm{Ca}$ & $\mathrm{P}$ \\
\hline $\begin{array}{l}\text { Terneiros } \\
\text { (desmame } \\
\text { precoce) }\end{array}$ & 100 & 0,900 & 1,63 & 0,55 & Deficiente & Deficiente \\
\hline Terneiros & 170 & 1,000 & 0,80 & 0,35 & Deficiente & Deficiente \\
\hline \multirow{2}{*}{ Novilhos } & \multirow{2}{*}{250} & 0,300 & 0,21 & 0,13 & Suficiente & Marginal a Deficiente \\
\hline & & 0,800 & 0,36 & 0,19 & Deficiente no final do verão & Limitante a Deficiente \\
\hline \multirow{2}{*}{ Novilhos } & \multirow{2}{*}{320} & 0,300 & 0,19 & 0,12 & Suficiente & Marginal a limitante. \\
\hline & & 0,800 & 0,30 & 0,16 & Suficiente & Limitante a Deficiente \\
\hline \multirow{2}{*}{ Novilhos } & \multirow{2}{*}{450} & 0,500 & 0,19 & 0,12 & Suficiente & Marginal a Limitante \\
\hline & & 1,000 & 0,27 & 0,15 & Suficiente & Limitante a Deficiente \\
\hline
\end{tabular}

*NRC (1996).

Ciência Rural, v.36, n.4, jul-ago, 2006. 
No caso de vacas de cria, conforme o NRC (1996), as exigências de cálcio variam de 0,15\% MS (vacas secas) a 0,25\% MS (no pico da lactação). Assim, considerando vacas de $450 \mathrm{~kg}$ de PV, com partos de primavera e com produção no pico de lactação de 4,5 ou 9,0 litros de leite por dia, observa-se que os teores de cálcio nas pastagens são adequados durante todos os meses do ano (Figura 1).

Os teores de fósforo nas pastagens estudadas variaram de 0,04 a $0,19 \%$, e os teores médios de acordo com os meses amostrados são apresentados na tabela 1. Os valores mais altos de fósforo foram observados no mês de dezembro $(\mathrm{P}<0,05)$, o que coincide com o final da primavera. Estes valores foram semelhantes aos observados nos meses de janeiro, fevereiro, março e setembro. Nos meses de outono e inverno, ocorreu uma tendência de serem observados valores mais baixos.

No presente trabalho, foram observados teores de fósforo mais altos na primavera, intermediários no verão e um pouco mais baixos no outono e no inverno. Esses resultados estão de acordo com observações de COATES et al. (1990), de que as concentrações de fósforo declinam com o avanço da maturidade das plantas. Além disso, segundo UNDERWOOD \& SUTTLE (1999), as maiores concentrações de fósforo ocorrem nas fases iniciais e nos períodos de maior crescimento das plantas, situação típica dos meses de final de primavera.

CAVALHEIRO \& TRINDADE (1992) encontraram teores médios de fósforo nas pastagens nativas de $0,11 \%$ a $0,14 \%$ nas diferentes estações do ano. Ainda, BARCELLOS et al. (1996) encontraram teores de fósforo no campo nativo da região da Campanha do RS variando de 0,07 a $0,16 \%$, entre os

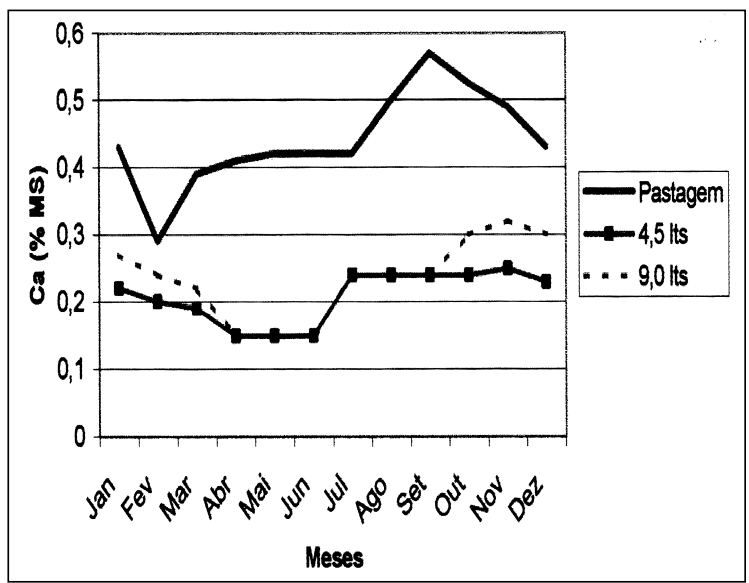

Figura 1 - Balanço mineral do cálcio nas pastagens nativas dos Campos de Cima da Serra para vacas de cria com partos de primavera, em duas situações de produção de leite no pico da lactação (NRC, 1996). meses de maio a outubro. SENGER et al. (1996), em onze unidades de mapeamento de solos no RS, encontraram concentrações de fósforo nas pastagens de 0,12 a $0,13 \%$ na primavera e de $0,10 \%$ nas outras estações. Outros trabalhos na mesma região deste trabalho (Campos de Cima da Serra) demonstraram teores médios de fósforo nas pastagens levemente superiores (PRATES et al., 1979, HERINGER \& JACQUES, 2002). Portanto, os níveis de P deste experimento, foram, em geral, inferiores aos obtidos pelos autores citados.

Ao serem comparados os níveis de fósforo encontrados nas pastagens com as exigências de bovinos de corte em crescimento e terminação estimadas pelo NRC (1996), constata-se que a pastagem não é capaz de suprir adequadamente nenhuma destas categorias animais em todos os meses analisados (Tabela 2). Deve ser salientado que o consumo total de matéria seca pelo animal deve ser considerado no cálculo do balanço de qualquer mineral, pois, conforme a qualidade da pastagem, o nível de consumo pode apresentar variações significativas e, conseqüentemente, influenciar a ingestão diária do mineral. Neste experimento, por meio do NRC (1996), foi utilizado um nível de consumo de matéria seca de 2,7\% do peso vivo para os ajustes do balanço mineral. Segundo SPEARS (1994), as tabelas de exigências geralmente superestimam as necessidades de fósforo. Assim, pode-se supor que a pastagem poderá não ser limitante para as categorias menos exigentes, em função do pastejo seletivo dos animais. No entanto, deve-se considerar que, durante a época de crescimento das pastagens, quando a maior disponibilidade de energia e proteína permite que os animais obtenham maiores ganhos de peso, ocorre um incremento na exigência em minerais. Ao contrário, em períodos de carência de energia e proteína na pastagem, os animais perdem peso e as exigências em minerais são menores.

Em vacas de cria com partos de primavera, com $450 \mathrm{~kg}$ de PV e com produção no pico de lactação de 4,5 (0,17\% P na MS) ou de 9,0 litros de leite por dia (0,21\% de P na MS), observa-se que os teores de fósforo das pastagens analisadas foram insuficientes durante todos os meses do ano, até para vacas secas (Figura 2). Uma simulação do balanço do fósforo, para a mesma vaca de cria, agora mantida em três níveis de consumo de matéria seca, ainda resultou numa deficiência em todos os meses do ano (Tabela 3). Portanto, considerando os altos valores encontrados para a relação Ca:P e os níveis muito deficientes de fósforo nas pastagens para todas as categorias analisadas, é clara a necessidade de suplementação dos animais para este elemento. 


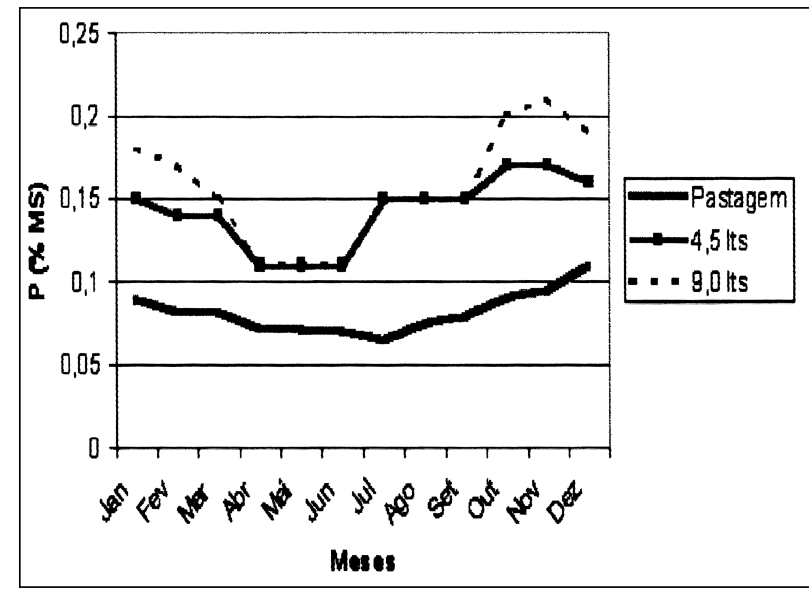

Figura 2 - Balanço mineral do fósforo nas pastagens nativas dos Campos de Cima da Serra para vacas de cria com partos de primavera, em duas situações de produção de leite no pico da lactação (NRC, 1996).

Os teores de enxofre nas pastagens estudadas variaram de 0,05 a $0,13 \%$. Na tabela 1 , são apresentados os valores médios deste elemento. Os teores mais altos de enxofre $(\mathrm{P}<0,05)$ foram observados nos meses de janeiro (início do verão) e dezembro (final da primavera), mas estes não foram diferentes do teor observado no mês de julho. As menores concentrações $(\mathrm{P}<0,05)$ ocorreram em abril (correspondente a meados do outono) e setembro (final do inverno), e valores intermediários em fevereiro, março e maio (verão e outono).

Embora não tenham apresentado um comportamento linear, os teores de enxofre estão de acordo com a afirmação de GEORGIEVSKII et al. (1982) de que o conteúdo deste mineral decresce no período vegetativo das pastagens, o qual, neste trabalho, ocorreu de abril a setembro.

Os valores encontrados para o enxofre, neste experimento, foram semelhantes aos observados por CAVALHEIRO \& TRINDADE (1992), que obtiveram teores de $0,09 \%$ nas pastagens naturais de diversas

Tabela 3 - Concentração de fósforo na matéria seca do alimento necessária para atender as exigências de uma vaca de cria de $450 \mathrm{~kg}$ e com produção de leite de 4,5 litros/dia, submetida a três níveis de consumo em relação ao peso vivo e ao balanço mineral considerando a pastagem nativa dos Campos de Cima da Serra.

\begin{tabular}{ccccc}
\hline & & & & \\
Consumo & Consumo diário & & & \\
MS (\% PV) & MS (kg) & g/d & $\%$ MS & \\
\cline { 3 - 4 } & & 20 & 0,22 & Deficias de P \\
Minerale \\
2,0 & 9,0 & 20 & 0,17 & Deficiente \\
2,5 & 11,2 & 20 & 0,14 & Deficiente \\
\hline 3,0 & 13,5 & & & \\
\hline
\end{tabular}

regiões do RS nas diferentes épocas do ano. No entanto, SENGER et al. (1997), avaliando pastagens de onze unidades de mapeamento de solos no RS, encontraram concentrações de enxofre superiores às obtidas neste trabalho, de 0,15 a $0,18 \%$ na primavera, de $0,23 \%$ no verão, de $0,13 \%$ no outono e de $0,14 \%$ no inverno, demonstrando as grandes variações regionais, o que sugere estudos localizados para identificar o perfil mineral dos pastos.

A partir do balanço dos níveis de enxofre encontrados nas pastagens, com a exigência de bovinos de corte, estimada em 0,15\% pelo NRC (1996), constata-se que a pastagem não é capaz de suprir adequadamente nenhuma das categorias avaliadas em qualquer época do ano, caracterizando um quadro de deficiência com provável redução da ingestão de forragem, pela menor síntese de proteína bacteriana no rúmen.

Os teores de sódio nas pastagens estudadas variaram de 4 a 618 ppm. Foram detectadas diferenças $(\mathrm{P}<0,05)$ entre os meses amostrados (Tabela $1)$. As concentrações mais altas de sódio $(P<0,05)$ foram observadas no mês de dezembro (final da primavera), e as mais baixas $(\mathrm{P}<0,05)$ ocorreram em setembro (final do inverno). Nos outros meses do ano, os valores foram intermediários.

Os valores de sódio encontrados neste trabalho foram inferiores aos observados por CAVALHEIRO \& TRINDADE (1992), que obtiveram 554 ppm na primavera, 434 ppm no verão, 389 ppm no outono e 407 ppm no inverno, em pastagens nativas de 25 unidades de mapeamento de solos do RS. No entanto, PRATES et al. (1979) encontraram teores de sódio bem superiores aos deste trabalho, de 800ppm na primavera e no verão, na mesma região dos Campos de Cima da Serra. Esta grande diferença pode ser devida aos diferentes tipos de solo e da composição botânica destes locais.

Ao comparar-se os níveis de sódio das pastagens com as exigências tanto de bovinos de corte em crescimento e terminação como de vacas no terço final da gestação, estimadas em 600 a 800ppm pelo NRC (1996), como também com a exigência de vacas em lactação, estimadas em 1000ppm (NRC, 1996), pode ser constatado que a pastagem não é capaz de suprir adequadamente em qualquer época do ano, nenhuma das categorias avaliadas. Portanto, com o fornecimento de sal comum à vontade aos animais, estas deficiências serão corrigidas.

Os teores de magnésio nas pastagens estudadas variaram de 522 a 1769ppm, e os teores médios deste elemento são apresentados na tabela 1 . 
As concentrações mais baixas $(\mathrm{P}<0,05)$ ocorreram em abril (correspondente a meados do outono) e setembro (final do inverno), mas ambas não diferiram dos outros meses de coleta.

A pequena variação observada nos teores de magnésio das pastagens no decorrer do ano parece concordar com a afirmação de UNDERWOOD \& SUTTLE (1999) de que as concentrações deste mineral declinam com a maturidade da planta, mas em menor proporção que as de outros minerais. Assim, os maiores teores de magnésio seriam observados nas fases iniciais de crescimento das pastagens. Entretanto, os resultados deste trabalho não confirmam a afirmação de que os teores de magnésio geralmente aumentam com a idade da planta.

HERINGER \& JACQUES (2002), na mesma região deste trabalho, encontraram teores médios um pouco superiores: de 1400 a 1700ppm de magnésio em pastagens nativas e de 3600ppm em pastagens melhoradas.

Ao comparar-se os níveis de magnésio nas pastagens com as exigências de bovinos de corte em crescimento e terminação, estimadas em 1000ppm pelo NRC (1996), constata-se que a pastagem é capaz de suprir adequadamente estas categorias animais em quase todos os meses do ano. Entretanto, para vacas no terço final da gestação, constata-se que a pastagem apresenta teores inferiores aos necessários em todas as épocas do ano, mas isto pode não ser limitante se for possibilitado o pastejo seletivo dos animais. No entanto, a pastagem não é capaz de suprir adequadamente a categoria vacas em lactação, cuja exigência em magnésio está estimada em 2000 ppm (NRC, 1996).

\section{CONCLUSÕES}

As concentrações nas pastagens dos minerais estudados (Ca, P, S, Na e Mg) variaram com o mês de coleta. As concentrações de cálcio e magnésio nas pastagens foram suficientes para suprir as exigências de vacas secas e novilhos em crescimento e terminação. Entretanto, os níveis de magnésio podem ser insuficientes para vacas no final da gestação e no início da lactação. Os teores de cálcio são insuficientes para suprir as exigências de terneiros desmamados.

As concentrações de fósforo, enxofre e sódio nas pastagens foram muito baixas em todos os meses estudados, não sendo suficientes para atender às exigências mínimas de produção para todas as categorias de bovinos de corte consideradas.

\section{AGRADECIMENTOS}

À Bunge Fertilizantes/Serrana Nutrição Animal, pelo financiamento parcial deste trabalho.

\section{REFERÊNCIAS}

AGOSTINI, J.A.E. Estudo preliminar das concentrações de nutrientes minerais em solos e pastagens naturais ocorrentes em diferentes regiões do Rio Grande do Sul. 1976. 80f. Dissertação (Mestrado em Zootecnia) - Curso de Pós-graduação em Zootecnia, Universidade Federal de Santa Maria.

ASSOCIATION OFICIAL AGRICULTURAL CHEMISTS A.O.A.C. Official Methodos of Analysis the Association of Official Analytical Chemists. 14.ed. Washington, D.C, 1984. 1141p.

BARCELLOS, J.O.J. et al. Efeito da suplementação mineral durante o inverno nos níveis de fósforo ósseo e sangüíneo e no desempenho pós-desmame de bezerros de corte. Revista da Sociedade Brasileira de Zootecnia, Viçosa, v.25, n.5, p.9941006, 1996.

BARCELLOS, J.O.J. et al. Suplementação mineral de bovinos de corte em ambientes subtropicais. In: BARCELLOS, J.O.J. et al. Suplementação mineral de bovinos em regiões subtropicais. Porto Alegre : UFRGS, 2003. p.19-51.

CAVALHEIRO, A.C.L.; TRINDADE, D.S. Os minerais para bovinos e ovinos criados em pastejo. Porto Alegre: Sagra DC Luzzatto, 1992. 142p.

COATES, D.B. et al. Phosphorus and beef production in northern Australia. 7. The effect of phosphorus on the composition, yield and quality of legume-based pasture and their relation to animal production. Tropical Grasslands, Peak Crossing, v.24, p.209-220, 1990.

GAVILLON, O.; QUADROS, A.T.F. O cobre, o molibdênio e o sulfato inorgânico em pastagens nativas do Rio Grande do Sul. Anuário Técnico IPZFO, Porto Alegre, n.3, p.423-453, 1976.

GEORGIEVSKII , V.I. et al. Mineral nutrition of animals. London: Butterworths, 1982. 475 p.

HERINGER, I.; JACQUES, A.V.A. Qualidade da forragem de pastagem nativa sob distintas alternativas de manejo. Pesquisa Agropecuária Brasileira, Brasília, v.37, n.3, p.399-406, 2002.

McDOWELL, L.R. Minerals in animal and human nutrition. New York: Academic, 1992. 524p.

NATIONAL RESEARCH COUNCIL. Nutrient Requirements of Beef Cattle. 7.ed. Washington, DC: National Academy of Sciences / National Research Council, 1996. 234p.

NICODEMO, M.L.F. Cálculo de misturas minerais para bovinos. Campo Grande: EMBRAPA-CNPGC, 2001. 25p. (EMBRAPA-CNPGC. Documentos, 109).

PRATES, E.R. et al. Avaliação da forragem disponível das pastagens naturais do Rio Grande do Sul. In: 16A. REUNIÃO ANUAL DA SOCIEDADE BRASILEIRA DE ZOOTECNIA, Curitiba, 1979. Anais.... Curitiba, PR: SBZ, 1979, v.2, p.272.

SENGER, C.G.D.Teores minerais em pastagens do Rio Grande do Sul. I. Cálcio, fósforo, magnésio e potássio. Pesquisa 
Agropecuária Brasileira, Brasília, v.31, n.12, p.897-904, 1996.

SENGER, C.G.D. et al. Teores minerais em pastagens do Rio Grande do Sul. II. Sódio, enxofre, zinco, cobre, ferro e manganês. Pesquisa Agropecuária Brasileira, Brasília, v.32, n.1, p.101108, 1997.

SPEARS, J.W. Minerals in forage. In: FAHEY JR., G.C. (Ed.) Forage quality, evaluation and utilization. Madison, American Society of Agronomy. NATIONAL CONFERENCE ON FORAGE QUALITY, EVALUATION AND UTILIZATION, 1994. p.281-317.

SPSS. User's guide: Statistics. SPSS Inc Version 11.5. Headquarters. Chicago. IL. 2002. 1 CD.
TEDESCO, M.J. et al. Análise de solo, plantas e outros materiais. 2. ed. Porto Alegre: UFRGS, 1995. 174 p (Boletim Técnico de Solos, 5).

TOKARNIA, C.H. et al. Deficiências minerais em animais de fazenda, principalmente bovinos em regime de campo. Pesquisa Veterinária Brasileira, Seropédica, v.20, n.3, p.127-138, 2000.

UNDERWOOD, E.J.; SUTTLE, N.F. The mineral nutrition of livestock. 3. Ed. New York: CABI, 1999. 601p.

WUNSCH, C. et al. Microminerais para bovinos de corte nas pastagens nativas dos Campos de Cima da Serra, RS, Brasil. Ciência Rural, Santa Maria, v.35, n.4, p.903-908, 2005. 